\title{
КАЧЕСТВЕННОЕ ВНЕДРЕНИЕ КРІ. ДАНЬ МОДЕ ИЛИ ФУНДАМЕНТ УСПЕШНОЙ ДЕЯТЕЛЬНОСТИ ПРЕДПРИЯТИЯ
}

\section{HIGH-QUALITY IMPLEMENTATION OF KPI. A TRIBUTE TO FASHION OR THE FOUNDATION OF A SUCCESSFUL ENTERPRISE}

\section{Sukhoterin}

Summary. The employee's motivation system, focused on the development strategy, ultimately consists of a set of KPIs for which he is responsible, and the assessment of their implementation affects the final bonus. Thus, it is the KPI that is the system that will help employees achieve their goals, and the management will regulate the workflow. KPI has a better control over the work of employees, which is considered and justified in this article.

Keywords: motivation system, KPI, development strategy, control, employee motivation.

\author{
Сухотерин Дмитрий Александрович \\ Директор, TOO «ROSS-COMPUTERS» \\ dmitriy_sa@mail.ru
}

Аннотация. Система мотивации работника, ориентированная на стратегию развития, в конечном итоге состоит из набора KPI, за которые он отвечает, и оценка их выполнения влияет на итоговую премию. Таким обра3ом, именно KPI и является той системой, которая поможет сотрудникам достигать поставленных целей, а руководству — регулировать рабочий процесс. KPI имеет более совершенный контроль над работой сотрудников, что рассмотрено и обосновано в данной статье.

Ключевые слова: система мотивации, КРІ, стратегия развития, контроль, мотивация сотрудников. д ля каждого сотрудника организация четко формулирует миссию и основные цели, которые повышают ответственность и мотивацию сотрудника. Для сбалансированности целей, осознания их исполнителями различных уровней, обеспечения реализации, первоочередное внимание необходимо уделять построению иерархии (дерева) целей как главному этапу ее создания. Определяющее условие при формировании «дерева целей», которое обеспечивает высокий уровень результата их достижения, обеспечение сбалансированности, взаимосвязи между целями различных уровней.

В современных условиях возрастает потребность В комплексном исследовании основных процессов функционирования предприятия, что позволяет оценить эффективность деятельности и определить основные направления оптимизации его бизнес-процессов.

Практика свидетельствует, что использование традиционных подходов по измерению и анализу ключевых процессов функционирования компании не позволяет всесторонне оценить имеющуюся ситуацию и разработать эффективные управленческие решения по оптимизации деятельности компании в будущие периоды времени.
Реализация стратегических планов компании предусматривает периодическое оценивание достигнутых результатов согласно экономически обоснованным нормативным значениям в рамках научно определенной системы статистических показателей.

В основе указанного подхода лежит предложенная Питером Друкером система оценки реализации целей компании путем достижения определенных нормативных значений в рамках системы ключевых показателей деятельности. Предложенная ученым система оценки получила название «Ключевые показатели эффективности» (KPI).

Система KPI дает возможность оценивать и контролировать деловую активность сотрудников, отдельных структурных подразделений и компании в целом. В развитых странах мира, решению этой проблемы уделяется значительное внимание, в то же время отечественные компании не делают необходимые акценты на внедрении указанного подхода. Именно поэтому тема является актуальной с целью применения данного метода КРІ в российских компаниях.

В крупных западных компаниях, где мотивационные процессы четко детализированы и формализованы, 


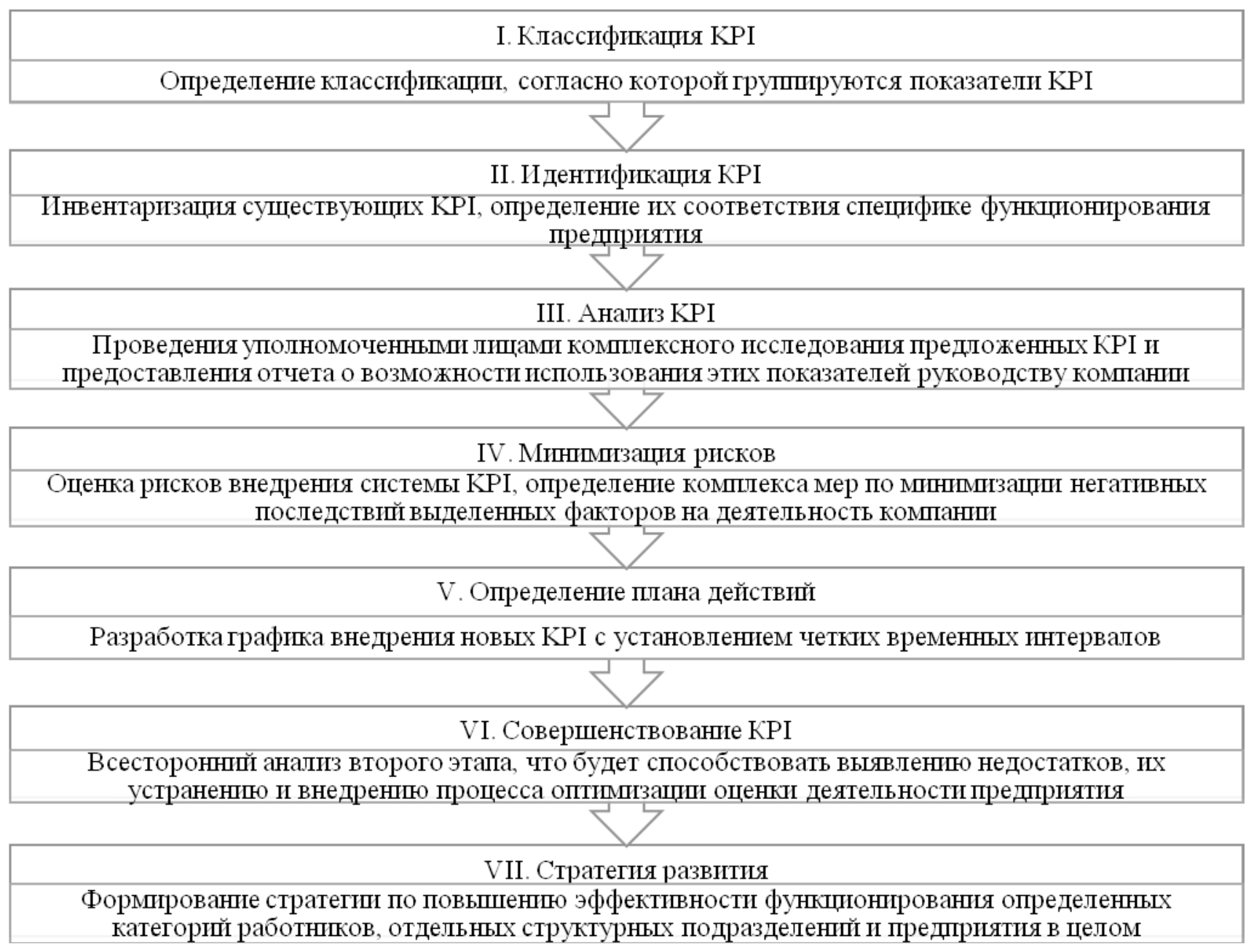

Рис. 1. Основные этапы введения КРІ [3]

благодаря KPI каждый сотрудник понимает, за что и какой размер вознаграждения он может получить. В рамках KPI каждый работник имеет четко определенные персональные задачи, а также установленные сроки их выполнения, благодаря чему компания имеет возможность контролировать его деятельность [2].

Использование ключевых показателей эффективности передовыми компаниями мира в последние годы объясняется универсальностью данного подхода и возможностью оптимизировать любые бизнес-процессы на уровне конкретного предприятия. Использование комплексной статистической информации, выделение основных показателей для отдельных категорий работников, различных структурных подразделений и предприятия в целом дает возможность менеджерам соответствующих уровней всесторонне анализировать существующие процессы, оценивать имеющиеся процессы в краткосрочной, среднесрочной и долгосрочной перспективе. На основе полученных результатов, принимать стратегические решения.
При внедрении системы КРІ на предприятии необходимо четко придерживаться последовательности выполнения ключевых этапов и обеспечивать все научно обоснованные мероприятия. На рисунке 1 представлены основные этапы внедрения системы ключевых показателей эффективности на предприятии.

Комплексный анализ деятельности предприятия с помощью KPI предусматривает отбор указанной системы статистические показатели исходя из:

- уровня исследования (категории работников, отдельные структурные подразделения или предприятие в целом)

- периода исследования (краткосрочный, среднесрочный или долгосрочный)

- деятельности (экономическая, финансовая, маркетинговая или управления персоналом) и т.д.

Для достижения стратегических целей предприятия необходимо построить научно обоснованную систему показателей, которая является целостной и сбаланси- 


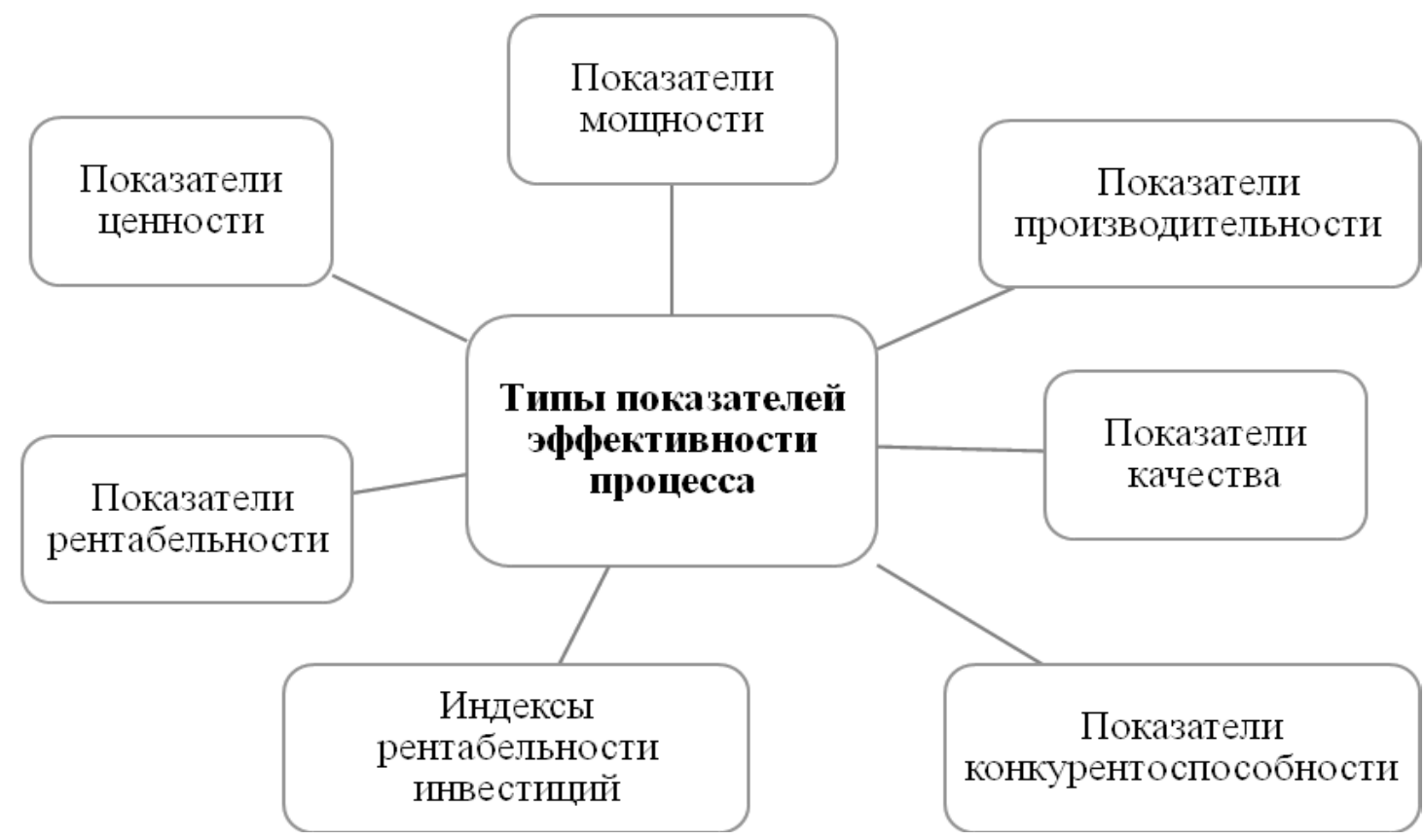

Рис. 2. Типы показателей эффективности процесса [7]

рованной, то есть позволяет всесторонне исследовать ключевые бизнес-процессы. На рисунке 2 представлены основные типы показателей, на основе которых строится конкретная система KPI предприятия.

Указанная система показателей базируется на принципах эффективности использования количественных, стоимостных, трудовых и временных ресурсов компании, ее отдельных структурных подразделений. Рассмотрим более детально представленные показатели:

І. Показатели мощности характеризуют производство товаров или услуг за определенный период времени (месяц, квартал, год).

II. Показатели производительности показывают соотношение между результатами, которые были получены в результате функционирования одного работника, отдельного структурного подразделения или предприятия в целом и затратами времени на получение этих результатов.

III. Показатели качества - это индикаторы, которые рассчитываются как соотношение между продукцией без определенных дефектов и общему объему продукции.

IV. Показатели конкурентоспособности характеризуют уровень конкуренции и позиции компании на конкретном рынке.

V. Показатели рентабельности характеризуют соотношение между прибылью и общим объемом продаж.
VI. Среди показателей рентабельности отдельно необходимо выделить индексы рентабельности инвестиций (ROI) - соотношение между прибылью и инвестициями, которые были осуществлены компанией.

VII. Показатели ценности исчисляются путем расчета средних значений рейтинговой оценки, которая базируется на оценке клиентами отдельных товаров или услуг компании по определенным признакам (стоимостными, потребительскими, и др.).

Указанная группа показателей базируется на оценке уровня удовлетворенности клиентов определенными товарами или услугами. Значение полученных рейтинговых оценок находятся в пределах от 0 до 1, что позволяет оценить отношение клиентов к отдельному товару или услуги среди всего ассортимента компании, или определить место предприятия по отдельной товарной позиции в сравнении с конкурентами [1].

Соблюдение научно обоснованных методологических положений при разработке и внедрении КРI на предприятии позволяет достичь определенных положительных изменений по ключевым направлениям его деятельности и, как следствие, оптимизировать деятельность компании (рис. 3).

В современных условиях существует мощный рынок бизнес-аналитики, который позволяет использовать имеющуюся статистическую информацию предприя- 


\section{ОСНОВНЬЕ РЕЗУ ЛЬТАТЫПРЕДПРИЯТИЯ}

\section{ЭКОНОМИЧЕСКАЯ ДЕЯТЕЛЬНОСТЬ}

•1. Увеличенне прнбыли

•2. Оптимнзация затрат в целоми по отдельным подразделениям

-3. Сокращенне окупаемости капнтала

• 4. Приведенне в соответствие с экономнческой целесообразностьюуровня

автоматизацни пр оизводственных пр оцессов

\section{ФИНАНСОВАЯ ДЕЯТЕЛЬНОСТЬ}

-1. Увеличенне уровней рентабельности в целом и по отдельным видам деятельности

• 2. Улучшение коэффициентов деловой активности

•3. Оптимизация структуры капитала

$\bullet 4$. Улучшение инвестищионных критериев

\section{УПРАВЛЕНИЕПЕРСОНАЛОМ}

•1. Увеличение эффективности коммуникаций между руководствоми работниками

2. Оптимизация затрат на персонал

•3. Усиленне мотивацин работников

•4. Оптимпзация кадровой политкки

Рис. 3. Основные результаты по ключевым направлениям деятельности предприятия при внедрении $\mathrm{KPI}[4]$

тия для повышения эффективности его деятельности и получения конкурентных преимуществ над другими предприятиями, которые функционируют на определенном рынке.

Основными преимуществами успешного внедрения ключевых показателей эффективности деятельности $\mathrm{KPI}$ является то, что мотивация работников напрямую зависит от достижения целей предприятия [4].

Представлена система КРІ имеет следующие преимущества:

1. Полученные показатели дают возможность руководству контролировать все этапы функционирования компании.

2. Система показателей обеспечивает оптимизацию принятия управленческих решений.
3. Указанная система показателей направлена на повышение эффективности всех процессов предприятия.

4. KPI обеспечивают оперативное и всестороннее понимание процессов компании.

5. Показатели эффективности процесса в будущем могут служить в качестве измерителей передового опыта компании.

6. Научно обоснованная система КРІ может быть использована для построения визуализированного отчета (dashboard), который дает возможность проанализировать деятельность компании.

Среди других преимуществ этой системы стоит отметить следующие [5]:

- понятность критериев оценивания уровня выполнения заданий 
Таблица 1. Примеры определенных целей и КРІ для структурных подразделений предприятия при построении системы мотивации КРI

\begin{tabular}{|l|l|l|}
\hline Отдел & Цели & KРI \\
\hline Бухгалтерия & $\begin{array}{l}\text { Основной целью применения КРІ является: } \\
\text { правильность ведения управленческого } \\
\text { и финансового учета }\end{array}$ & $\begin{array}{l}\text { Результаты налоговых проверок } \\
\text { Получение качественной оперативной информации } \\
\text { по данным учета }\end{array}$ \\
\hline Отдел продаж & $\begin{array}{l}\text { Целями применения КРІ является выполнение } \\
\text { сбытового плана, минимизация дебиторской } \\
\text { задолженности }\end{array}$ & $\begin{array}{l}\text { Уровень выполнения плана по объему продаж } \\
\text { группы продукции, прирост продаж относительно } \\
\text { аналогичного периода прошлого года, объем } \\
\text { реализации продукции, уровень дебиторской } \\
\text { задолженности }\end{array}$ \\
\hline Отдел маркетинга & $\begin{array}{l}\text { Целями разработки КРІ является рост доли рынка } \\
\text { и доходов, повышение степени удовлетворенности } \\
\text { потребителей }\end{array}$ & $\begin{array}{l}\text { Изменение сегмента рынка по направлениям, } \\
\text { количеству продуктов; приростом потребительской } \\
\text { базы; рост количества закупок }\end{array}$ \\
\hline
\end{tabular}

- наглядность оценивания компетенций

понятность перспектив карьерного роста

- повышение уровня мотивированности успеха во время обучения

- чувство значимости своей работы, а также движения вперед или движения назад.

Наряду с рядом преимуществ, которые предоставляет предприятию KPI, также существует ряд недостатков.

К основным недостаткам следует отнести:

1. Значительные затраты финансовых, трудовых и временных ресурсов при внедрении и администрировании системы оценки.

2. Научно необоснованные акценты на небольшом количестве показателей.

3. Субъективное оценивание определенных процессов в компании за счет использования разнообразных методов исчисления статистических показателей.

4. Невозможность оценить с помощью количественных показателей отдельные результаты деятельности работников, определенных структурных подразделений и предприятия в целом.

5. Установление ложных пороговых значений показателей эффективности [6].

При разработке системы мотивации персонала предприятия с использованием KPI, предлагаем придерживаться следующих рекомендаций:

1. Формирование стратегии. Выделение задач для отдельных структурных подразделений

2. Разработка плана мероприятий и проекта системы KPI:

- Разработка плана мероприятий;

- Создание специальной рабочей группы

- Определение промежуточных результатов работы и вознаграждения за них
- Определение конечных результатов работы и вознаграждение за них

3. Определение перечня подразделений в организационной структуре предприятия, к которым будет применяться мотивационная составляющая:

- Определение направлений работы данных подразделении

- Разработка и построение дерева целей

4. Выбор и разработка порядка расчета ключевых показателей эффективности для отдельных подразделений:

- Определение «ключевых» показателей

- Обоснование порядка расчета ключевых показателей

5. Выбор методики для расчета KPI: план-факт, таблицы значений, формулы нормативу, линейная методика, коэффициент результативности.

6. Определения премии с помощью выбранной методики:

- Определение степени влияния каждого КРI

- Оценка фактических значений KPI

На этапе выбора структурных подразделений, для которых будет разрабатываться мотивационная схема, должны быть четко определены конкретные цели для данных подразделений. Так предлагаются следующие цели табл. 1.

Вместе с тем важным является определение заработной платы, а также соотношения фиксированной и переменной частей. Последняя часть вознаграждения должна составлять не менее $30 \%$ от оклада. В экономической литературе существуют несколько вариантов расчета оплаты труда по системе ключевых показателей эффективности.

По нашему мнению, наиболее приемлемым для работников предприятия является вариант, с учетом всех 
показателей уровней эффективности в трех проекциях. Эти проекции подразделяются на следующие: базовое значение (нулевая точка) начала отсчета результата; нормативное значение (определенное с учетом ситуации на рынке, особенностей и сложности работы, возможностей работника) должно быть удовлетворительным; цели - сверхнормативный уровень (стремление работника).

Таким образом, КРІ - это измеритель того, как достигнута та или иная цель, так как эффективная работа сотрудников означает получение компании по прибыли.

Использование системы КРІ для оценки деятельности отдельных категорий работников, определенных структурных подразделений и предприятия в целом является важным этапом, поскольку позволяет провести комплексный анализ существующих процессов и разработать стратегию их оптимизации в будущие периоды времени.

При формировании системы KPI необходимо учитывать специфику каждого бизнес-процесса, которое будет способствовать повышению качества исследования и позволит сформировать достоверные выводы. Для достижения поставленных целей целесообразно воспользоваться BІ-платформой, что позволит построить качественную инфографику исследуемых процессов.

Необходимость внедрения КPI обусловлена быстросменными условиями в области информационных технологий. Постоянные изменения технологий и повышения уровня конкурентоспособности требуют от предприятия соответствующей реакции, что приводит к повышению требований относительно профессионально-квалификационного уровня работников.

\section{ЛИТЕРАТУРА}

1. Анисимова Н.А., Смотрова Т.И. Опыт и проблемы внедрения инновационных систем оплаты труда на основе грейдов и КРІ. В сборнике: Актуальные проблемы развития отраслевых рынков: национальный и региональный уровень. Сборник статей V Международной научно-практической конференции. Под редакцией Т.Н. Гоголевой. Воронеж, 2021. С. 6-11.

2. Ахиджак М.А., Дьяков С.А. Применение системы КРІ для оценки эффективности деятельности фирмы в современных условиях. В сборнике: Проектный и инвестиционный менеджмент в постпандемический период. Материалы II Национальной научно-практической конференции. Краснодар, 2021. С. 23-29.

3. Павлова Т.И. Архитектура КРІ для банков. В сборнике: Инновационные технологии, экономика и менеджмент в промышленности. сборник научных статей VI международной научной конференции. Волгоград, 2021. С. 161-163.

4. Титкова Е.Ф. Повышение эффективности системы мотивации персонала организации в современных условиях // В сборнике: Экономика и государство: эффективное управление и взаимодействие Сборник статей. Под ред. Т.М. Степанян. Москва, 2019. С. 319-322.

5. Уткина Ю.С. Система КРІ для управления персоналом в сфере образования. Технологии Образования. 2021. № 1 (11). С. $123-131$.

6. Ц Цой Д.Г., Пьянкова Л.А. Мотивация и стимулирование труда персонала // В сборнике: Роль и место информационных технологий в современной науке. Сборник статей Международной научно-практической конференции. 2019. С. 189-193.

7. Чернышева Е.А. Характеристика системы мотивации персонала в организации // В сборнике: Закономерности и тенденции инновационного развития общества. Сборник статей по итогам Международной научно-практической конференции. 2019. С. 176-177.

() Сухотерин Дмитрий Александрович (dmitriy_sa@mail.ru ).

Журнал «Современная наука: актуальные проблемы теории и практики» 